NBSIR 75.659

\title{
A New Mode of Chipping Fracture in Brittle Solids, and Its Application in a Model for Wear Under Fixed Abrasive Conditions I. Mode of Chipping Fracture II. Wear Model
}

B. R. Lawn

Inorganic Materials Division Institute for Materials Research National Bureau of Standards Washington, D. C. 20234

February 1975

Interim Report for Period July 1, 1974 through June 30, 1975

Prepared for

Department of the Navy

Office of Naval Research

Arlington, Virginia 22217 
Lảwh, B. R., Swain, M. V., Philips, K., On the mode of chipping fracture in britte solids, J. Mater Sci. Lett. 10, 1236-1239 (1975).

313.

16306 HSIR. $75-659$

Lawn, B. R., A model for the wear of brittle solids under fixed abrasive conditions, Wear Short Commun. 33, 369-372 (1975).

$$
120 \%-659340
$$


NBSIR 75-659

A NEW MODE OF CHIPPING FRACTURE

IN BRITTLE SOLIDS, AND ITS APPLICATION

IN A MODEL FOR WEAR UNDER FIXED

ABRASIVE CONDITIONS

I. MODE OF CHIPPING FRACTURE

II. WEAR MODEL

B. R. Lawn

Inorganic Materials Division

Institute for Materials Research

National Bureau of Standards

Washington, D. C. 20234

February 1975

Interim Report for Period July 1, 1974 through June 30, 1975

Prepared for

Department of the Navy

Office of Naval Research

Arlington, Virginia 22217

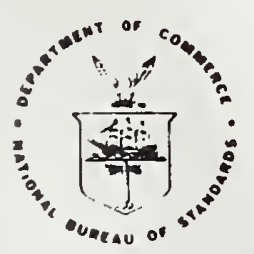

U. S. DEPARTMENT OF COMMERCE, Frederick B. Dent, Secretary 

I. On the Mode of Chipping Fracture in Brittle Solids 

Chipping processes in brittle solics, despite their unquestionable relevance to a diversity of technologies from ceramics finishing to geological engineering, are not well understood at the fundamental level. Some recent studies of microfracture patterrs beneath standard hardness indenters do, however, provide some insight into the problem ${ }^{1,2}$, and it is our objective here to indicate how this insight may be applied to construct a physical model of chipping fracture. Essentially, the picture which emerges is that depicted in Fig. 1: (i) Upon loading the indenter, a confined zone of irreversible (plastic) deformation forms about any sharp points or corners (thereby accounting for the residual hardness impression), from which "median vent" cracks first initiate and subsequently propagate radially outward along suitable planes of symmetry (e.g. as defined by the diagonals of a pyramid indenter, or by preferred cleavage planes) containing the contact axis; (ii) Upon unloading the indenter, the median vents close up, but, just prior to complete removal, "lateral vent" cracks initiate and extend laterally from the deformation zone toward the specimen surface. Of the two types of cracking it is clearly the second which relates more directly to brittle chipping. Yet up till now a detailed fracture mechanics analysis has been attempted only for the median vent system. This system is relatively well defined, since the indentation stress field, which uniquely determines the extent of crack growth ${ }^{1}$, can reasonably be represented in terms of the classical Boussinesq field for normal point loading ${ }^{2}, 3$. On the basis of the fundamental Griffith energy-balance condition for fracture 4 , it may readily be argued that brittle cracks will generally 
tend to follow trajectories of the lesser principal stresses within the indentation field, such that the path maintains near-orthogonality to a component of major tension: the best studied illustration of this principle is the Hertzian cone crack 5,6 , which, in the absence of any deformation-induced nucleation center, initiates from an incipient surface flaw and flares downward into the specimen. In the scheme of Fig. 2, in which the principal stresses are defined such that $\sigma_{11} \geqslant \sigma_{22} \geqslant \sigma_{33}$ (positive values denoting tension) nearly everywhere, median vent geometry may be specified in terms of families of $\sigma_{11}$ and $\sigma_{33}$ trajectories, cone crack geometry in terms of families of $\sigma_{22}$ and $\sigma_{33}$ trajectories.

The conditions under which the lateral vents form are, unfortunately, less easily modelled. Since the lateral system operates only as the indenter is withdrawn from the specimen surface it is evident that the driving force for propagation must originate from some residual stress field associated with the irreversible deformation zone. This conclusion is substantiated by microscopic investigation of the damage patterns as a function of indenter geometry (e.g. "sharp" or "blunt"): in general, the extent of lateral venting is found to increase markedly with expanding zone size. A graphic illustration of the effect is obtained by loading a soda-lime glass plate with a small ( lmm diam.) spherical indenter: at comparatively low load the contact is elastic, and the only fracture is that of cone cracking, whereas at higher load some plasticity develops beneath the penetrating sphere, and lateral venting becomes evident in the unloaded plate. ${ }^{1}$ A related effect was reported by $\mathrm{Culf}^{7}$, who observed otherwise 
regular cone cracks in glass to deflect upward ("hat brim" effect) upon sudden release of the indenter load. Culf also observed considerable residual stress birefringence in association with this phenomenon, over distances large compared with the scale of the deformation zone itself. That residual stresses exist about hardness impressions in most brittle materials has been amply demonstrated by a number of strain-sensitive techniques ${ }^{8}$. That these stresses can also be moderately long-range in nature is seen most clearly in the distances over which relaxation by plastic flow (e.g. dislocation loop punching) occurs in annealing experiments ${ }^{9}$. Neither the existence nor the intensity of the residual elastic fields should come as any surprise, for the stress levels achieved beneath the indenter in hardness tests on highly brittle solids tend to be of the order of the intrinsic bond strength of the structure ${ }^{10,11}$, and the relief of these high stresses would ideally require the impressed region to restore completely to its original unstrained state.

These observations, coupled with a reexamination of the Boussinesq field, provide us with a working model upon which to base an analysis of lateral vent formation. We note that the lateral vents extend in all cases on surfaces closely delineated by families of $\sigma_{11}$ and $\sigma_{22}$ trajectories in Fig. 2 (although the paths are modified somewhat by the deformation zone itself, and by free surfaces, including any preexisting median vents or cone cracks); it is as if the applied load were actually reversed upon indenter withdrawal, so that the $\sigma_{33}$ stress normal to the lateral vent becomes the dominant component of tension in the filed. Of course, it is 
physically meaningless to associate a reversed applied load with a surface in the unloaded state, but an effectively similar net result may obtain if the deformation zone were to act as a center of contraction with respect to the surrounding elastic matrix. This effect is depicted schematically in Fig. 3. The distribution of stresses at the zone boundary must inevitably depend strongly on the nature of the irreversible deformation (which itself remains an issue of some controversy ${ }^{11,} 12$ ). Nevertheless, one can proceed by making reasonable assumptions as to this distribution (e.g. that the tractions are of constant magnitude, and are directed such that the net force is zero), and evaluate the residual field in the matrix by taking expressions for the stresses due to elemental point forces (e.g. Mindlin ${ }^{13}$ ) and integrating around the boundary. One may then construct a stress trajectory pattern for the field, in analogy to Fig. 2, and thereby trace out prospective fracture paths from the deformation zone. Full details of such calculations will be discussed elsewhere; we simply report here that the predicted paths do indeed curve toward the specimen surface in essentially the manner shown in Fig. 1.

The scope of the present model extends well beyond the establishment of a suitable basis for evaluating an "index of brittleness" in standard hardness testing ${ }^{14}$. It provides physical insight into a number of seemingly unrelated phenomena in brittle solids:

(i) Strength degradation. Surface damage introduced into a brittle surface as a result of contact (either static or impact) with hard particles constitutes a potential source of weakness. The mechanics of the damage process may be conveniently simulated in a simple indentation test $^{15}$. 
(ii) Glass cutting. A glass cutter's wheel is designed to produce a continuous "trailing" median vent as a linear starting crack for subsequent plate fracture in flexure. However, lateral venting invariably occurs in the wake of the moving "indenter", thereby damaging the edges of the final cut. Clearly, the need here is for a neans of suppressing the chipping mode.

(iii) Surface removal processes. Individual chipping events in the machining, drilling, grinding, abrasion, erosion and wear of brittle surfaces in general (e.g. ceramics, gemstones, rocks) are of the type depicted in Fig. $I^{l}$. By summing over an appropriate distribution of such microscopic events, it should be possible to describe macroscopic surface removal parameters at a fundamental level.

(iv) Geophysical impact phenomena. Meteorite-induced craters ranging in scale from geological land masses ${ }^{16}$ to lunar fines ${ }^{17}$ bear a resemblance to the damage pattern in Fig. I which can only be described as striking. While thermal and stress-wave effects associated with the high-velocity impacts are undoubtedly important factors in these cases ${ }^{18}$, the possible role of residual stresses about the central "deformation zone" in determining crater morphology may warrant further attention.

Institute for Materials Research

B. R. Lawn

National Bureau of Standards

Washington, D. C. 20234

U. S. A.

Martin Marietta Laboratories

M. V. Swain

1450 South Rolling Road

Baltimore, Md. 21227

U. S. A.

Division of Materials Science

K. Phillips

University of Sussex

Falmer, Sussex BNI 9QT

England 
1. Lawn, B. R. and Wilshaw, T. R., J. Mater. Sci., in the press.

2. Lawn, B. R. and Swain, M. V., J. Mater. Sci., in the press.

3. Boussinesq, J., Application des Potentiels a l'Etude de l'Equilibre et du Mouvement des Solides Elastiques, (Gauthier-Villars, Paris, 1885). Discussed in Timoshenko, S. P. and Goodier, J. N., Theory of Elasticity (McGraw-Hill, New York, 1970), pp. 398-402.

4. Griffith, A. A., Phil. Trans. Roy. Soc. Lond., A211, 163 (1920).

5. Hertz, H., J. Reine Angew. Math., 92, 156 (1881): Verhandlungen des Vereins zur Beforderung des Gewerbe Fleisses, 61, 449 (1882). Reprinted in English, in Hertz's Miscellaneous Papers (Macmillian, London, 1896), Chs. 5, 6 .

6. Frank, F. C. and Iąwn, B. R., Proc. Roy. Soc. Lond., A299, 291 (1967).

7. Culf, C. J., J. Soc. Glass.Tech., 41, 157 (1957).

8. Hockey, B. J., in The Science of Hardness Testing and its Research Applications, Symposium Proceedings, Eds. Westbrook, J.H. and Conrad, H. (American Society for Metals, Metals Park, 1973), Ch. 3.

9. Wagatsume, R., Sumino, K., Uchida, W. and Yamamoto, S. J. Appl. Phys., 42,222 (1971).

10. Kelly, A., Strong Solids (Clarendon, Oxford, 1966).

11. Hill, M. J. and Rowcliffe, D. J., J. Mater. Sci., in the press.

12. Ernsberger, F. M., Ann. Rev. Mat. Sci.', 2, 529 (1972).

13. Mindlin, R. D., Physics, 7,195 (1936).

14. Westbrook, J.H., in The Science of Hardness Testing and its Research Applications, Symposium Proceedings, Eds. Westbrook, J.H. and Conrad, H. (American Society for Metals, Metals Park, 1973), pp. $491-494$. 
15. Evans, A. G., J. Amer. Ceram. Soc., 56, 405 (1973).

16. Nadai, A., Theory of Flow and Fracture of Solids (McGraw-Hill, New York, 1963), pp. 247-249.

17. Carter, J. L. and MacGregor, I. D., Proc. Apollo 11 Lunar Sci. Conf., 1,247 (1970).

18. Vedder, J. F. and Mandeville, J.-C., J. Geophys. Res., 79, 3247 (1974). 


\section{Figure Captions}

1. Fracture geometry beneath sharp indenter. Central deformation zone shown as dark region, median vent cracks as broken lines, lateral vent cracks as heavy lines. (a) Section view schematic, (b) plan view schematic, (c) surface view of fused silica indented with sharp, irregular particle (scanning electron micrograph, field width $3 \mathrm{~mm}$ ).

2. Stress trajectories (curves whose tangent indicates direction of principal stress) for Boussinesq field, showing half-surface view (top) and section view (bottom). Cone cracks initiate from incipient surface flaws and propagate everwhere orthogonally to $\sigma_{11}$ (tensile outside contact area), median vents initiate from central deformation zone and propagate orthogonally to $\sigma_{22}$ (tensile below contact zone), lateral vents initiate from deformation zone and propagate nearly orthogonally to $\sigma_{33}$ (compressive everywhere, but tensile if applied load reversed).

3. Schematic representation of distribution of mismatch tractions at boundary between central deformation zone and surrounding elastic matrix, at indenter withdrawal. 

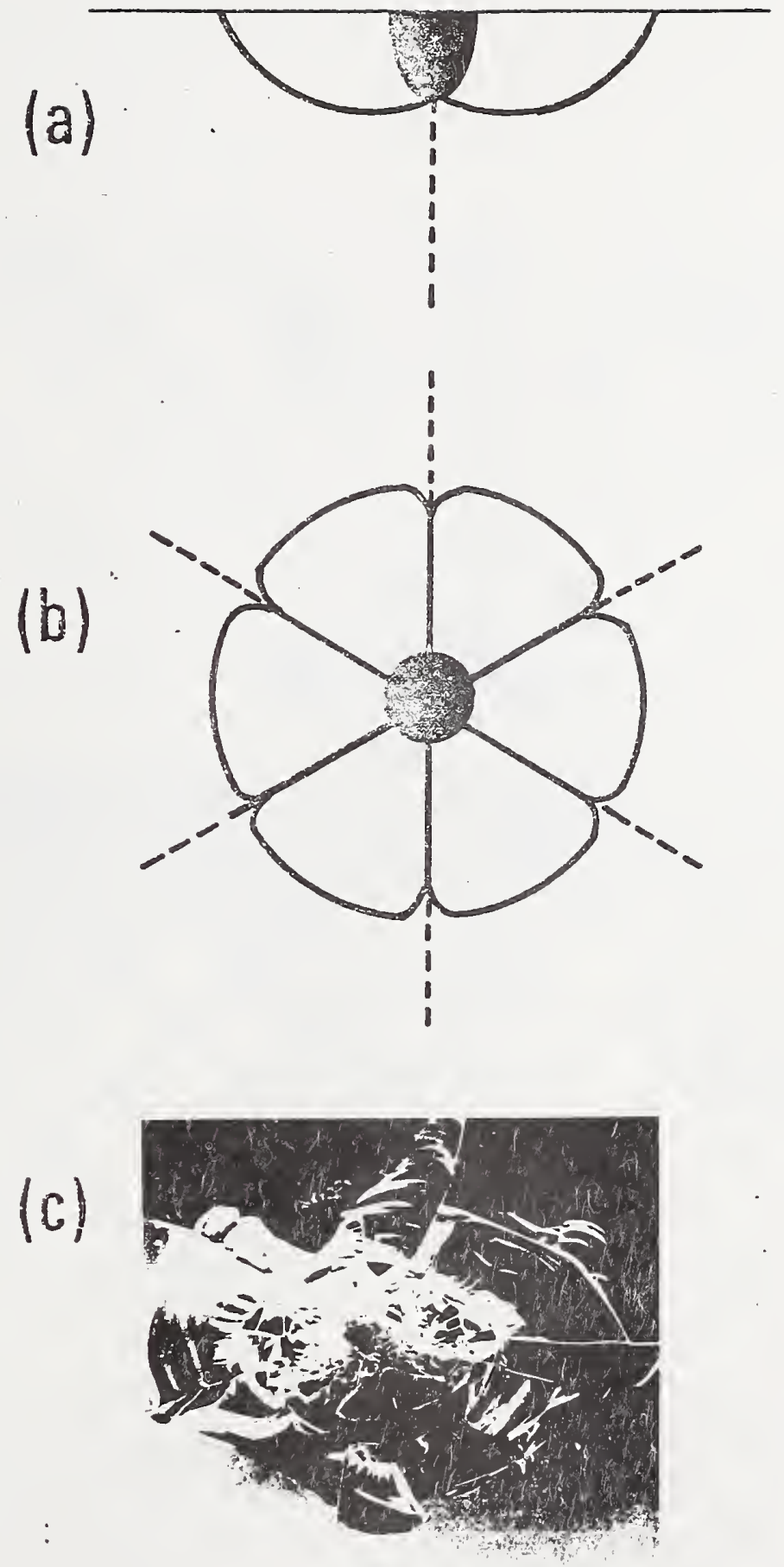

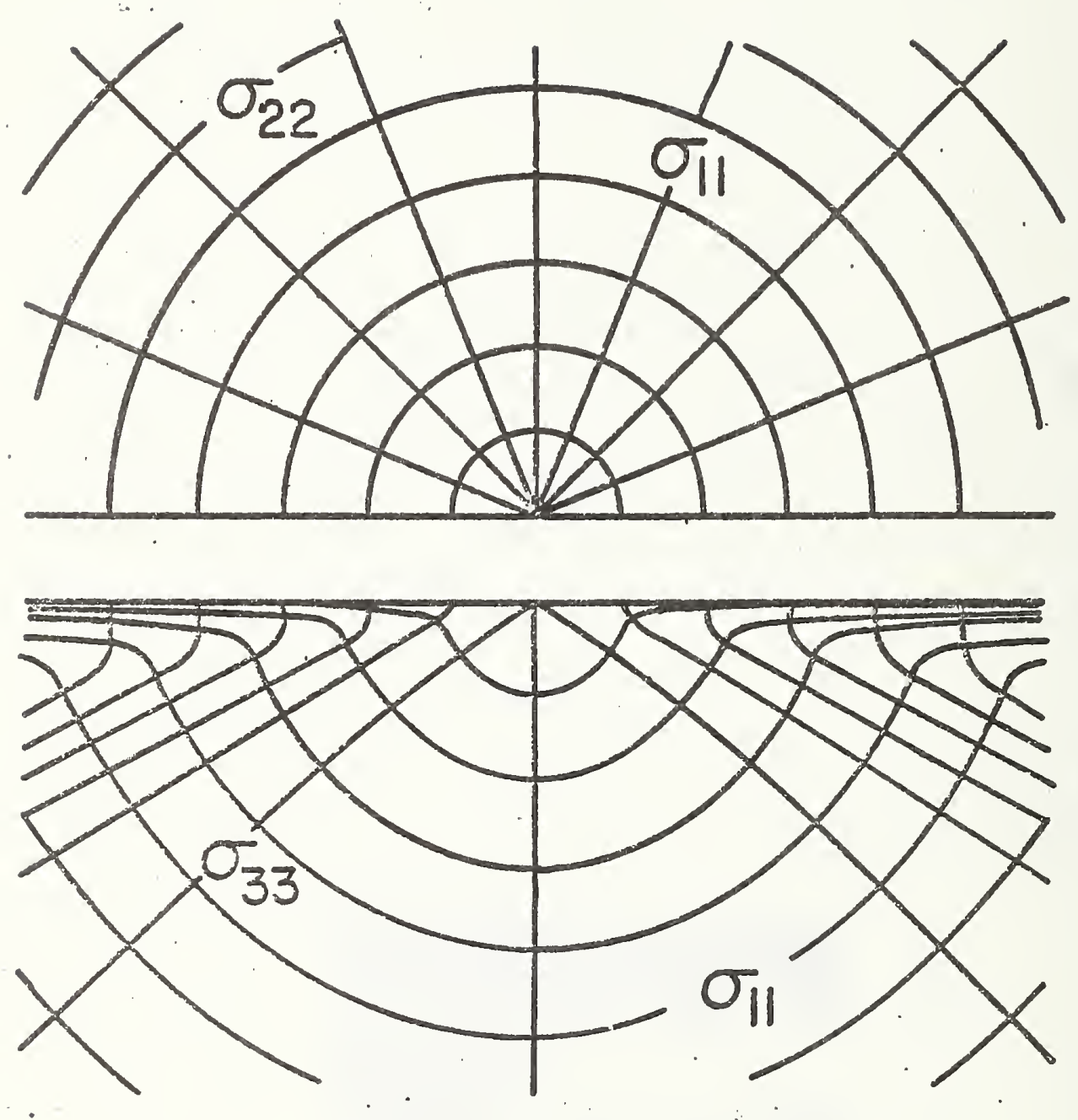


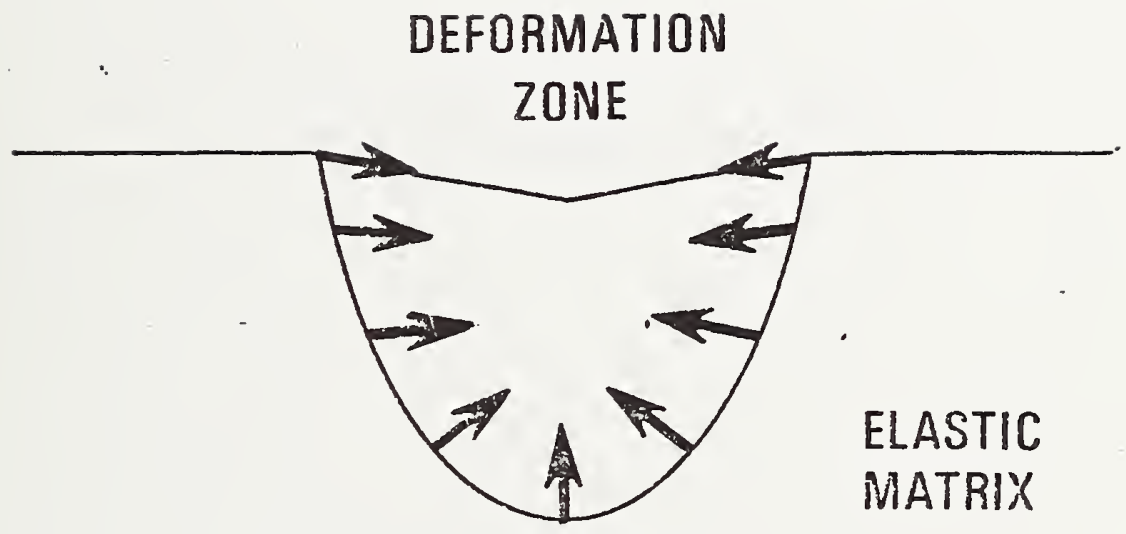


II. A Model for the Wear of Brittle Solids Under Fixed Abrasive Conditions 

Other than that the wear mechanism involves some microfracturing, and the wear rate is remarkably high, relatively little is known about the abrasion of highly brittle solids ${ }^{1,2}$; this despite intense current interest in the machining and finishing of brittle surfaces within the ceramics engineering industry ${ }^{3}$. However, with the advent of "indentation fracture mechanics" a new approach has become available for investigating a wide range of small-scale cracking phenomena ${ }^{4}$. The purpose of the present note is to use this approach to construct an explicit model of the wear process in brittle solids, for the simple case of a "fixed" abrasive medium ("two-body" process) in which the grit particles are "ideally sharp."

A schematic representation of the wear mechanism is given in Figure 1. Macroscopically, one measures the wear rate $\underline{\mathrm{V}}=\mathrm{dV} / \mathrm{d} \underline{\underline{t}} \underline{\underline{V}}=$ volume removed) appropriate to a specified total load $\underline{P}$ and velocity $\mathrm{v}_{0}$ for the abrasive medium relative to the specimen. Microscopically, attention focusses on the individual chip-removal mechanism, characterized by an "indenter" load $\underline{P}_{i}$ and velocity $v_{0}$ (all "indenters" traverse the specimen with the same velocity in the two-body configuration). The idea is to start with a mechanical description of the removal process for the $\underline{i}$ th indenter, and thence to sum over all such $\underline{i}$ events to predict the macroscopic behavior.

To this end we resort to observations in "model" brittle solids (notably glass) of the fracture patterns beneath standard sharp indenters (e.g. cones, pyramids) 5,6 , to build up the following picture. We consider the sliding particle i to produce a "plastic" 
deformation track of width $\underline{a}_{i}$. Then, for geometrically similar impressions, the mean indentation pressure at any instant of contact may be identified with the material hardness ${ }^{7}$,

$$
\underline{\mathrm{p}}_{\mathrm{i}}=\underline{\underline{\mathrm{p}}}_{\mathrm{i}} / \underline{\alpha} \underline{\mathrm{a}}_{\mathrm{i}}^{2} \approx \underline{H}_{i}
$$

where $\alpha$ is a factor determined by indenter geometry. Upon unloading, residual stresses, associated with incompatibility between deformation zone and surrounding elastic matrix, initiate and propagate lateral, chip-forming cracks (so-called "lateral vents": other cracks form on loading, but these extend straight downward, and play only a secondary role in chipping). In this view, the size of the prospective chip is determined by the configuration of the hardness impression, so the chip area may be written

$$
\underline{A}_{i}=\underline{n} \underline{a}_{i}^{2}
$$

where $\underline{n}$ is a linear scaling factor. The volume of material removed by the indenting particle in traversing through a distance $\Delta$ \& in an interval of time $\Delta \underline{t}$ is $\Delta \underline{V}_{i}=\underline{A}_{i} \underline{l}_{\text {, }}$ whence, from (1) and (2),

$$
\dot{v}_{i}=\Delta \underline{V}_{i} / \Delta t=A_{i} \Delta l / \Delta t=\left(\underline{n} \underline{v}_{0} / \underline{\alpha} \pi \underline{H}\right) \underline{\underline{P}}_{i} .
$$

A straightforward summation operation now gives the macroscopic wear rate; 


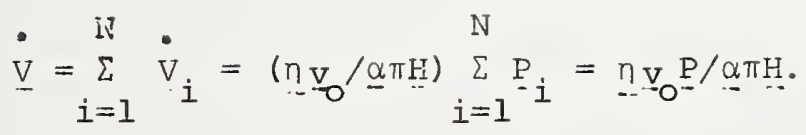

This equation may be rearranged,

$$
\dot{\mathrm{V}} / \mathrm{v}_{\mathrm{O}} \mathrm{P}=\underline{\mathrm{n}} / \bar{\alpha} \pi \underline{\mathrm{H}}
$$

such that the left and right sides conveniently represent macroscopic and microscopic parameters respectively. " It would thus appear possible to predetermine the abrasive wear rate of brittle ceramics simply from quantities measured in standard hardness testing procedures. Some data from soda-lime glass illustrate the principle. Taking $\underline{\mathrm{H}} \approx 1.0 \times 10^{10} \mathrm{Nm}^{-2}$ ("dynamic" hardness) $)^{8}, \underline{\alpha} \approx 1$ (conical particles), $\underline{n} \approx 1$, we predict $\underline{\underline{n}} \underline{\alpha} \underline{\underline{H}} \approx 3 \times 10^{-11} \mathrm{~m}^{2} \mathrm{~N}^{-1}$ as the wear rate. This compares with $\underline{\mathrm{V}} / \mathrm{v}_{\mathrm{O}} \mathrm{P} \approx 1 \times 10^{-11} \mathrm{~m}^{2} \mathrm{~N}^{-1}$ measured under test conditions in which chipping is pronounced (namely, spherical specimens on an alumina grinding block pre-ground with $45 \mu \mathrm{m}$ diamond paste, decyl alcohol environment, at $\left.\underline{\mathrm{P}}=10 \mathrm{~N}, \underline{\mathrm{v}}_{0}=1 \mathrm{~ms}^{-1}\right)^{9}$.

There are some interesting implications associated with the present model :

(i) The calculated wear rate is independent of the (apparent) area of contact between work tool and specimen, and also of the number and size of indenting particles. Thus, all arbitrariness and complication of a statistical analysis is avoided. Physically, this

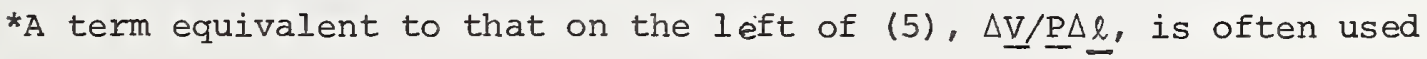
as an alternative expression of the macroscopic wear rate.
} 
arises because of the essential "linearity" of the fixed-abrasive wear mechanism: the chip volume is proportional to the load on the indenting particle, so that the total volume removed does not depend on the way in which the total load is distributed.

(ii) The analysis tacitly assumes that the intensity of the residual stress field about the deformation track is sufficiently high to drive the chip-forming cracks to the surface. The indication from indentation fracture mechanics studies ${ }^{10}$ is that the extent of microcracking relative to the size of the deformation zone diminishes with decreasing load. Thus we might anticipate a brittle-to-ductile, chipping-to-ploughing transition in wear mechanism at low abrasion loads, small particle sizes, with an attendant fall in wear rate to a value more typical of non-brittle solids ${ }^{l}$. Again, it has been assumed that geometrical similarity is preserved in the indentation fracture process. In practice, initially sharp particles tend to become "blunt" (either by fragmentation or by clogging with debris), and intersections tend to occur between neighboring tracks, as abrasion proceeds; these effects will further reduce the wear rate. (iii) Most significantly, the wear rate under ideal chipping conditions is uniquely determined by the material hardness; by controlling the scale of the crack pattern behind the indenting particle, the "plasticity" properties of the material assume a key role in the abrasion process. However, hardness is a rate-dependent quantity which can change markedly with the conditions of testing, e.g. environment, load rate (sliding velocity), etc. ${ }^{8,11}$ This bears strongly on the 
correlations between a wide range of chemo-mechanical properties (e.g. machining, drilling, grinding) and the hardness of brittle materials reported by Westwood and co-workers ${ }^{12}$. While the present model may provide a sound basis for interpreting chemo-mechanical phenomena, it needs to be emphasised that correlations of this type can be truly meaningful only if the hardness values are measured under conditions pertinent to the macroscopic situation.

\section{Acknowledgements}

The author is indebted to S. M. Wiederhorn and H. H. Johnson for discussions on this work. The sponsorship by the Office of Naval Research, under Contract No. NR-032-535, is acknowledged. 


\section{Figure Captions}

1. Cross-sectional views of "fixed" abrasion process. (a) Macroscopic view: total load $\underline{\mathrm{P}}$ bears on specimen via abrasive grit particles bonded to tool. (b) Microscopic view: i th particle experiences load $\underline{P}_{i}$, and leaves in its wake a deformation track, width $2 \underline{a}_{i}$ " from which "lateral vents" propagate to form chip, section area $\underline{A}_{i} \cdot A I l$ particles translate across specimen surface with velocity $\mathrm{v}$. 
1. E. Rabinowicz, Friction and Wear of Materials, Wiley, New York, 1965 , Ch. 7 .

2. M. M. Kruschov, Wear, 28 (1974) 69.

3. The Science of Ceramic Machining and Surface Finishing, Symposium Proceedings, N. B. S. Special Publ. 348, 1972.

4. B. R. Lawn and T. R. Wilshaw, J. Mater. Sci. (in press).

5. B. R. Lawn and M. V. Swain, J. Mater. Sci. (in press).

6. B. R. Lawn, M. V. Swain and K. Phillips, to be published.

7. D. Tabor, The Hardness of Metals, Clarendon, Oxford, 1951, Ch. 1.

8. S. P. Gunasekera and D. G. Holloway, Phys. and Chem. Glasses, 14 (1973) 45 .

9. S. M. Wiederhorn and D. E. Roberts, Wear, 32 (1975) 51.

10. B. R. Lawn and E. R. Fuller, to be published.

11. R. E. Hanneman and J. H. Westbrook, Phil. Mag. 18 (1968) 73.

12. A. R. C. Westwood and N. H. Macmillan, The Science of Hardness Testing and its Research Applications, Symposium Proceedings, American Society for Metals, 1973, Ch. 28. 

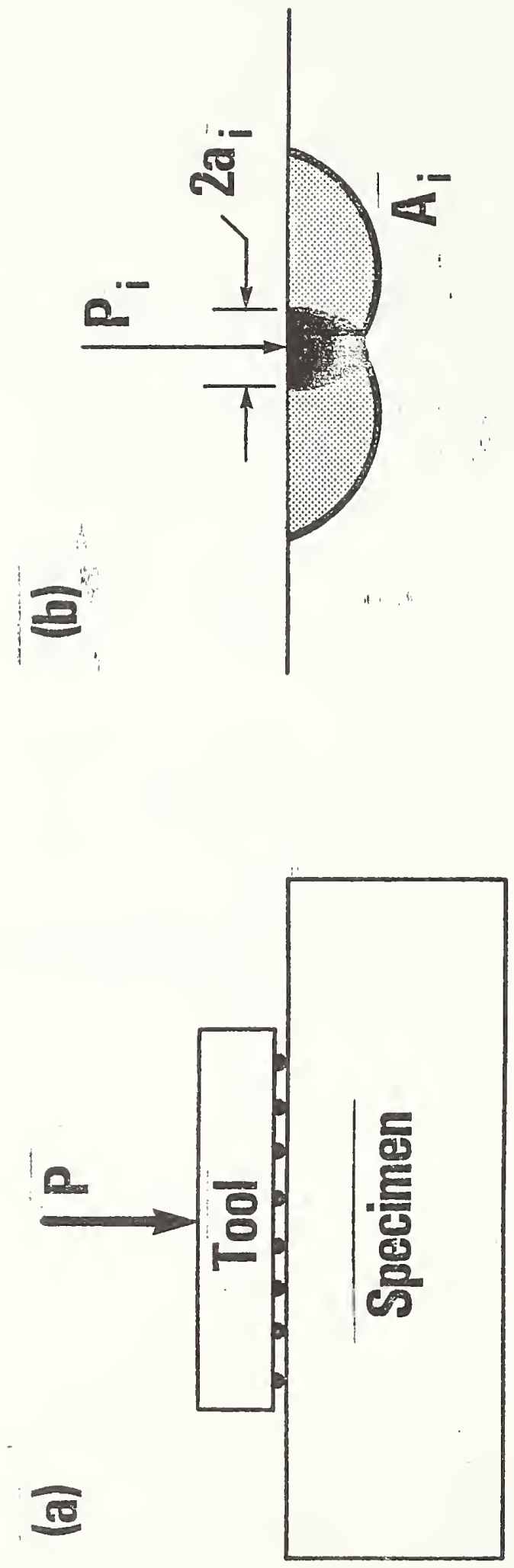


\section{A MODEL FOR THE WEAR OF BRITTLE SOLIDS}

\section{UNDER FIXED ABRASIVE CONDITIONS}

\section{B. R. Lawn*}

Institute for Materials Research, National Bureau of Standards, Washington, D. C. 20234, U.S.A.

*On study leave, from School of Physics, University of New South Wales, Kensington, N. S. W. 2033, A :Éralia 

other than that the wear mechanism involves some microfracturing, and the wear rate is remarkably high, relatively little is known about the abrasion of highly brittle solids ${ }^{1,2}$; this despite intense current interest in the machining and finishing of brittle surfaces within the ceramics engineering industry ${ }^{3}$. Howerer, with the advent of "indentation fracture mechanics" a new approach has become available for investigating a wide range of small-scale cracking phenomena ${ }^{4}$. The purpose of the present note is to use this approach to construct an explicit model of the wear process in brittle solids, for the simple case of a "fixed" abrasive medium ("two-body" process) in which the grit particles are "ideally sharp."

A schematic representation of the wear mechanism is given in Figure 1. Macroscopically, one measures the wear rate $\underline{v}=d \underline{V} / d \underline{t}(\underline{V}=$ volume removed) appropriate to a specified total load $\underline{P}$ and velocity $\mathrm{y}_{0}$ for the abrasive medium relative to the specimen. Microscopically, attention focusses on the individual chip-removal mechanism, characterized by an "indenter" load $\underline{P}_{i}$ and velocity $v_{0}$ (all "indenters" traverse the specimen with the same velocity in the two-body configuration). The idea is to start with a mechanical description of the removal process for the $\underline{i}$ th indenter, and thence to sum over all such i events to prediat the macroscopic behavior.

To this end we resort to observations in "model" brittle solids (notably glass) of the fracture patterns beneath standard sharp indenters (e.g. cones, pyramids) 5,6 , to build up the following picture. We consider the sliding particle $\underline{i}$ to produce a "plastic" 
deformation track of width $\underline{a}_{i}$. Then, for geometrically similar impressions, the mean indentation pressure at any instant of contact may be identified with the material hardness ${ }^{7}$,

$$
\underline{p}_{i}=\underline{p}_{i} / \underline{\alpha} \pi \underline{\underline{a}}_{i}^{2} \approx \underline{H}_{1}
$$

where $\alpha$ is a factor determined by indenter geometry. Upon unloading, residual stresses, associated with incompatibility between deformation zone and surrounding elastic matrix, initiate and propagate lateral., chip-forming cracks (so-called "lateral vents"; other cracks form on loading, but these extend straight downward, and play only a secondary role in chipping). In this view, the size of the prospective chip is determinld by the configuration of the hardness impression, so the chip ared may be written

$$
\underline{A}_{i}=\underline{n} \underline{a}_{i}^{2}
$$

where $\underline{n}$ is a linear scaling factor. The volume of material removed by the indenting particle in traversing through a distance $\Delta \underline{\ell}$ in an interval of time $\underline{\Delta t}$ is $\underline{\Delta V} \underline{V}_{i}=\underline{A}_{i} \underline{l}_{\text {, }}$ whence, from (1) and (2),

$$
\underline{v}_{i}=\Delta \underline{V}_{i} / \Delta \underline{t}=\underline{A}_{i} \Delta \underline{l} / \Delta \underline{t}=\left(\underline{n} \underline{v}_{0} / \underline{\alpha} \pi \underline{H}\right) \underline{P}_{i} .
$$

A straightforward summation operation now gives the macroscopic 


$$
\dot{\mathrm{V}}=\sum_{i=1}^{\mathrm{N}} \dot{\mathrm{V}}_{i}=\left(\underline{n}_{\mathrm{v}} / \underline{\alpha} \pi \underline{\mathrm{H}}\right) \sum_{i=1}^{\mathrm{N}} \underline{\mathrm{P}}_{i}=\underline{n} \underline{\mathrm{v}}_{0} \underline{\mathrm{P}} / \underline{\alpha} \pi \underline{H} .
$$

This equation may be rearranged,

$$
\underline{\mathrm{V}} / \underline{\mathrm{v}}_{0} \underline{\mathrm{P}}=\underline{\underline{n}} / \underline{\alpha} \pi \underline{\mathrm{H}}
$$

such that the left and right sides conveniently represent macroscopic and microscopic parameters respectively. " It would thus appear possible to predetermine the abrasive wear rate of brittle ceramics simply from quantities measured in standard hardness testing procedures.

Some data from soda-lime glass illustrate the principle. Taking $\underline{H} \approx 1.0 \times 10^{10} \mathrm{Nm}^{-2}$ ("dynamic" hardness) ${ }^{8}, \underline{\alpha} \approx 1$ (conical particles), $\underline{n} \approx 1$, we predict $\underline{\underline{n}} \underline{\underline{\alpha}} \underline{\underline{H}} \approx 3 \times 10^{-11} \mathrm{~m}^{2} \mathrm{~N}^{-1}$ as the wear rate. This compares with $\underline{\mathrm{V}} / \underline{\mathrm{V}}_{\mathrm{O}} \mathrm{P} \approx 1 \times 10^{-11} \mathrm{~m}^{2} \mathrm{~N}^{-1}$ measured under test conditions in which chipping is pronounced (namely, spherical specimens on an alumina grinding block pre-ground with $45 \mu \mathrm{m}$ diamond paste, decyl al-cohol environment, at $\left.\underline{\mathrm{P}}=10 \mathrm{~N}, \mathrm{v}_{0}=1 \mathrm{~ms}^{-1}\right)^{9}$.

There are some interesting implications associated with the present model:

(i) The calculated wear rate is independent of the (apparent) area of contact between work tool and specimen, and also of the number and size of indenting particles. Thus, all arbitrariness and complication of a statistical analysis is avoided. Physically, this

*A term equivalent to that on the left of $(5), \underline{\Delta V} / \underline{P} \Delta \underline{l}$, is often used as an alternative expression of the macroscopic wear rate. 
arises because of the essential "Iinearity" of the fixed-abrasive wear mechanism: the chip volume is proportional to the load on the indenting particle, so that the total volume removed does not depend on the way in which the total load is distributed.

(ii) The analysis tacitly assumes that the intensity of the residual stress field about the jeformation track is sufficiently high to drive the chip-forming cracks to the surface. The indication from indentation fracture mechanics studies ${ }^{10}$ is that the extent of microcracking relative to the size of the deformation zone diminishes with decreasing load. Thus we might anticipate a brittle-to-ductile, chipping-to-ploughing transition in wear mechanism at low abrasion loads, small particle sizes, with an attendant fall in wear rate to a value more typical of non-brittle solids ${ }^{1}$. Again, it has been assumed that geometrical similarity is preserved in the indentation fracture process. In practice, initially sharp particles tend to become "blunt" (either by fragmentation or by clogging with debris), and intersections tend to occur between neighboring tracks, as abrasion proceeds; these effects will further reduce the wear rate. (iii) Most significantly, the wear rate under ideal chipping conditions is uniquely determined by the material hardness; by controlling the scale of the crack pattern behind the indenting particle, the "plasticity" properties of the material assume a key role in the abrasion process. However, hardness is a rate-dependent quantity which can change markedly with the conditions of testing, e.g. environment, load rate (sliding velocity), etc. ${ }^{8}, 11$ This bears strongly on the 
correlations between a wide range of chemo-mechanical properties (e.g. machining, drilling, grinding) and the hardness of brittle materials reported by Westwood and co-workers ${ }^{12}$. While the present model may provide a sound basis for interpreting chemo-mechanical phenomena, it needs to be emphasised that correlations of this type can be tu.ul." meaningful only if the hardness values are measured under conaitions pertinent to the macroscopic situation.

Acknowledgements

The author is indebted to S. M. Wiederhorn and H. H. Johnson for discussions on this work. The sponsorship by the office of Naval Research, undex Contract No. NR-032-535, is acknowledged. 
1. E. Rabinowicz, Friction and Wear of Materials, Wiley, New York, 1965, Ch. 7 .

2. M. M. Kruschov, Wear, 28 (1974) 69.

3. The Science of Ceramic Machining and Surface Finishing, Symposium Proceedings, N. E. S. Special Publ. 348, 1972.

4. B. R. Lawn and T. R. Wilshaw, J. Mater. Sci. (in press).

5. B. R. Law and M. V. Swain, J. Mater. Sci. (in press).

6. B. R. Iawn, M. V. Swain and K. Phillips, to be published.

7. D. Tabor, The Hardness of Netals, Clarendon, Oxford, 1951, Ch. 1.

8. S. P. Gunasekera and D. G. Holloway, Phys. and Chem. Glasses, 14 (1973) 45 .

9. S. M. Wiederhorn and D. E. Roberts, Wear, 32 (1975) 51.

10. B. R. Lawn and E. R. Fuller, to be published.

II. R. E. Hanneman and J. H. Westbrook, Phil. Mag. 18 (1968) 73.

12. A. R. C. Westwood and N. H. Macmillan, The Science of Haraness Testing and its Research Applications, Symposium Proceedings, American Society for Metals, 1973, Ch. 28. 


\section{Figure Captions}

1. Cross-sectional views of "fixed" abrasion process. (a) Macroscopic view: total load $\underline{p}$ bears on specimen via abrasive grit particles bonded to tool. (b) Microscopic view: i th particl.e experiences load $\underline{P}_{i}$, and leaves in its wake a deformation track, width $2 \underline{a}_{i}$ ' from which "lateral vents" propagate to form chip, section area $\underline{A}_{i}$. All particles translate across specimen surface with velocity $\mathrm{v}_{0}$. 

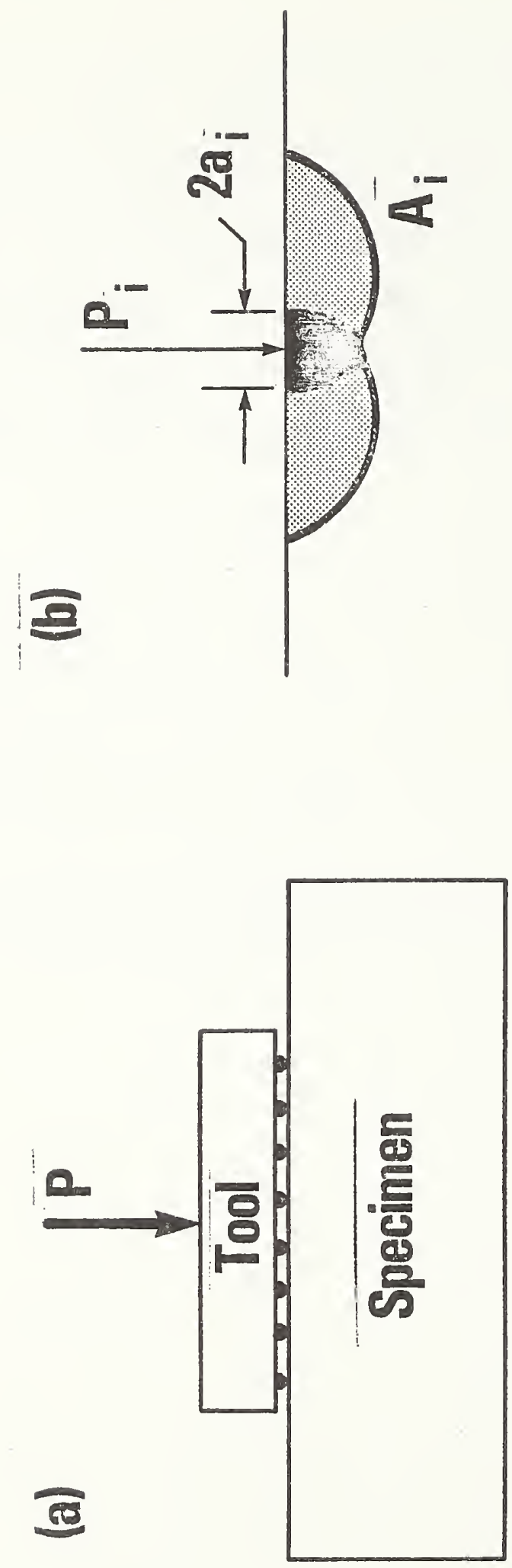


\section{On the Mode of Chipping Fracture in Brittle Solids}

Chipping processes in brittle solics, despite their linquestionable relevance to a diversity of technologies from ceramics finishing to geological engineering, are not well understood at the fundamental level. Some recent studies of microfracture patterrs beneath standard hardness indenters do, however, shed some light on the problem ${ }^{1}, 2$. Essentially, the picture which emerges is that depicted in Fig. 1:

(i) Upon loading the indenter a confined zone of irreversible (plastic) deformation forms about any sharp points or corners (thereby accounting for the residual hardness impression), from which "median vent" cracks first initiate and subsequently propagate radially outward along suitable planes of symmetry (e.g. as defined by the diagonals of a pyramid indenter, or by preferred cleavage planes) containing the contact axis; (ii) Upon unloading the indenter the median vents close up, but, just prior to complete removal, "lateral vent" cracks initiate and extend laterally from the deformation zone toward the specimen surface. Of the two types of cracking it is clearly the second which relates more directly to brittle chipping.

Yet up till now a detailed fracture mechanics analysis has been attempted only for the median vent system. This system is relatively well defined, since the indentation stress field, which uniquely determines the extent of crack growth ${ }^{1}$, can reasonably be represented in terms of the classical Boussinesq field for normal point loading ${ }^{2}, 3$. On the basis of the fundamental Griffith energy-balance condition for fracture 4 it'may readily be argued that brittle cracks will generally 
tend to fol.low trajectories of the lesser principal stresses within the indentation field, such that the path maintains near-orthogonality to a component of major tension: the best-studied illustration of this principle is the Hertzian cone crack 5,6 , which, in the absence of any deformation-induced nucleation center, initiates from an incipient surface flaw and flares downward into the specimen. In the scheme of Fig. 2, in which the principal stresses are defined such that $\sigma_{11} \geqslant \sigma_{2,2} \geqslant \sigma_{33}$ (positive values denoting tension) nearly everywhere, median vent geometry may be specified in terms of families of $\sigma_{11}$ and $\sigma_{33}$ trajectories, cone crack geometry in terms of families of $\sigma_{22}$ and $\sigma_{33}$ trajectories.

The conditions under which the lateral vents form are, unfortunately, less easily modelled. Since the lateral system operates only as the indenter is withdrawn from the specimen surface it is evident that the driving force for propagation must originate from some residual stress field associated with the irreversible deformation zone. This conclusion is substantiated by microscopic investigation of the damage patterns as a function of indenter geometry (e.g. "sharp" or "blunt"): in general, the extent of lateral venting is found to increase markedly with expanding zone size. A graphic illustration of the effect is obtained by loading a soda-lime glass plate with a small ( lmm diam.) spherical indenter: at comparatively low load the contact is elastic, and the only fracture is that of cone cracking, whereas at higher load some plasticity develops beneath the penetrating sphere, and lateral venting begins to extablish itself ${ }^{1}$. A manifestation of this behavior was reported by culf ${ }^{7}$, who observed otherwise 
regular cone cracks in glass to deflect upward ("hat krim" effect) upon sudden release of the indenter load. Culf also observed considerable residual stress birefringence in association with this phenomenon, over distances large compared with the scale of the deformation zone itself. That residual stresses exist about hardness impressions in most brittle materials has been amply demonstrated by a number of strain-sensitive techniques ${ }^{8}$. That these stresses can also be moderately long-range in nature is seen most clearly in the distances over which relaxation by plastic flow (e.g. dislocation loop punching) occurs in annealing experiments ${ }^{9}$. Neither the existence nor the intensity of the residual elastic fields should come as any surprise, for the stress levels achieved beneath the indenter in hardness tests on highly brittle solids tend to be of the order of the intrinsic bond strength of the structure ${ }^{10,11}$, and the relief of these high stresses would ideally require the impressed region to restore completely to its original unstrained state.

These observations, coupled with a reexamination of the Boussinesq field, provide us with the basis for an analysis of lateral vent geometry. We note that the lateral vents extend in all cases on surfaces closely delineated by families of $\sigma_{11}$ and $\sigma_{22}$ trajectories in Fig. 2 (although the paths are modified somewhat by the deformation zone itself, and by free surfaces, including any preexisting median vents or cone cracks); it is as if the applied load were actually reversed upon indenter withdrawal, so that the $\sigma_{33}$ stress normal to the lateral vent becomes the dominant component of tension in the filed. Of course, it is 
physically meaningless to associate a reversed applied load with a surface in the unloaded state, but an effectively similar net result, may obtain if the deformation zone were to act as a center of contraction with respect to the surrounding elastic matrix. This is depicted schematically in Fig. 3. The distribution of stresses at the zone boundary must inevitably depend strongly on the nature of the irreversible deformation, which itself remains an issue of some controversy 11,12 . Nevertheless, one can proceed by making reasonable assumptions as to this distribution (e.g. that the tractions are of constant magnitude, and are directed such that the net force is zero), and evaluate the residual field in the matrix by taking expressions for the stresses due to elemental point forces (e.g. Mindlin ${ }^{13}$ ) and integrating around the boundary. One may then construct a stress trajectory pattern for the field, in analogy to Fig. 2, and thereby trace out probable fracture paths from the deformation zone. Full details of such calculations will be discussed elsewhere; we simply report here that the predicted paths do indeed curve toward the specimen surface in essentially the manner shown in Fig. 1.

The scope of the present model extends well beyond the establishment of a suitable basis for evaluating an "index of brittleness" in standard harndess testing ${ }^{14}$. It provides physical insight into a number of seemingly unrelated phenomena in brittle solids:

\section{(i) Strength degradation. Surface damage introduced into a brittle} surface as a result of contact (either static or impact) with hard particles constitutes a potential source of weakness. The mechanics of the damage process mày be conveniently simulated in a simple indentation test $^{15}$. 
(ii) Glass cutting. A glass cutter's wheel is designed to produce a continuous "trailing" median vent as a linear starting crack for subsequent plate fracture in flexure. However, lateral venting invariably occurs in the wake of the moving "indenter", thereby damaging the edges of the final cut. Clearly, the objective here is to find a way of suppressing the chipping mode.

(iii) Surface removal processes. Individual chipping events in the machining, drilling, grinding, abrasion, erosion and wear of brittle surfaces in general (e.g. ceramics, gemstones, rocks) are of the type depicted in Fig. ${ }^{1}$. By suming over an appropriate distribution of such microscopic events it should be possible to describe macroscopic surface removal parameters at a fundamental level.

(iv) Gecphysical impact phenomena. Meteorite-induced craters ranging in scale from geological land masses $^{16}$ to lunar fines ${ }^{17}$ bear a resemblance to the damage pattern in Fig. 1 which can only be described as striking. While thermal and stress-wave effects associated with the high-velocity impacts are undoubtedly important factors in these $\operatorname{cases}^{18}$, the possible role of residual stresses about the central "deformation zone" in determining crater morphology may warrant further attention.

Institute for Materials Research

B. R. Lawn

National Bureau of Standards

Washington, D. C. 20234

U. S. A.

Martin Marietta Laboratories

M. V. Swain

1450 South Rolling Road

Baltimore, Md. 21227

U. S. A.

K. Phillips

Division of Materials Science

University of Sussex

Falmer, Sussex BNI 9QT

England 
1. Lawn, B. R. and Wilshaw, T. R., J. Mater. Sci., in the press.

2. Lawn, B. R. and Swain, M. V., J. Mater. Sci., in the press.

3. Boussinesq, J., Application des Potentiels a l'Etude de l'Equilibre et du Mouvement des Solides Elastiques, (Gauthier-Villars, Paris, 1885). Discussed in Timoshenko, S. P. and Goodier, J. N., Theory of Elasticity (McGraw-Hill, New York, 1970), pp. 398-402.

4. Griffith, A. A., Phil. Trans. Roy. Soc. Lond., A211, 163 (1920).

5. Hertz, H., J. Reine Angew. Math., 92, 156 (1881): Verhandlungen des Vereins zur Beforderung des Gewerbe Fleisses, 61, 449 (1882). Reprinted in English, in Hertz's Miscellaneous Papers (Macmillian, London, 1896), Chs. 5, 6 .

6. Frank, F. C. and Ląwr, B. R., Proc. Roy. Soc. Lond., A299, 291 (1967).

7. Culf, C. J., J. Soc. Glass.Tech., 41, 157 (1957).

8. Hockey, B. J., in The Science of Hardness Testing and its Research Applications, Symposium Proceedings, Eds. Westbrook, J.H. and Conrad, H. (American Society for Metals, Metals Park, 1973), Ch. 3.

9. Wagatsume, R., Sumino, K., Uchida, W. and Yamamoto, S. J. Appl. Phys. , 42,222 (1971).

10. Kelly, A., Strong Solids (Clarendon, Oxford, 1966).

11. Hill, M. J. and Rowcliffe, D. J., J. Mater. Sci., in the press.

12. Ernsberger, F. M., Ann. Rev. Mat. Sci., 2, 529 (1972).

13. Mindlin, R. D., Physics, 7, 195 (1936).

14. Westbrook, J. H., in The Science of Hardness Testing and its Research Applications, Symposium Proceedings, Eds. Westbrook, J. H. and Conrad, H. (American Society for Metals, Metals Park, 1973), pp. 491-494. 
15. Evans, A. G., J. Amer. Ceram.Soc., 56, 405 (1973).

16. Nadai, A., Theory of Flow and Fracture of Solids McGraw-Hill, New York, 1963), pp. 247-249.

17. Carter, J. I. and MacGregor, I. D., Proc. Apollo 11 Lunar Sci. Conf., 1, 247 (1970).

18. Vedder, J. F. and Mandeville, J.-C., J. Geophys. Res., 79, 3247 (1974). 


\section{Figure Captions}

1. Fracture geometry beneath sharp indenter. Central deformation zone shown as dark region, median vent cracks as broken lines, lateral vent cracks as heavy lines. (a) Section view schematic, (b) plan view schematic, (c) surface view of fused silica indented with sharp, irregular particle (scanning electron micrograph).

2. Stress trajectories (curves whose tangent indicates direction of principal stress) for Boussinesq field, showing half-surface view (top) and section view (bottom). Cone cracks initiate from incipient surface flaws and propagate everwhere orthogonally to $\sigma_{\text {II }}$ (tensile outside contact area), median vents initiate from central deformation zone and propagate orthogonally to $\sigma_{22}$ (tensile below contact zone), lateral vents initiate from deformation zone and propagate nearly orthogonally to $\sigma_{33}$ (compressive everywhere, but tensile if applied load reversed).

3. Schematic representation of distribution of mismatch tractions at boundary between central deformation zone and surrounding elastic matrix, at indenter withdrawal. 
(a)

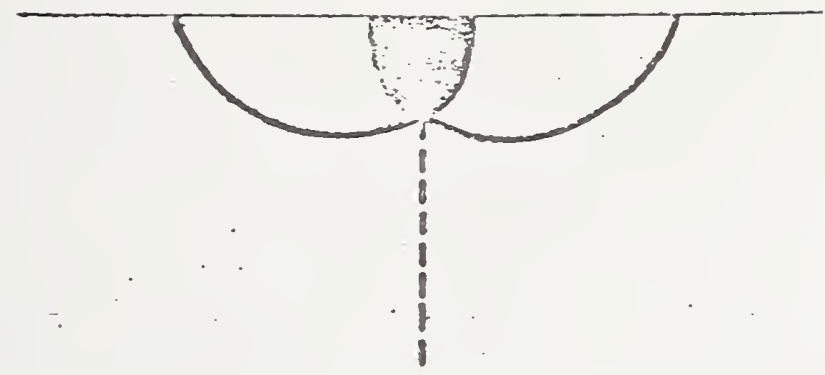

(b)
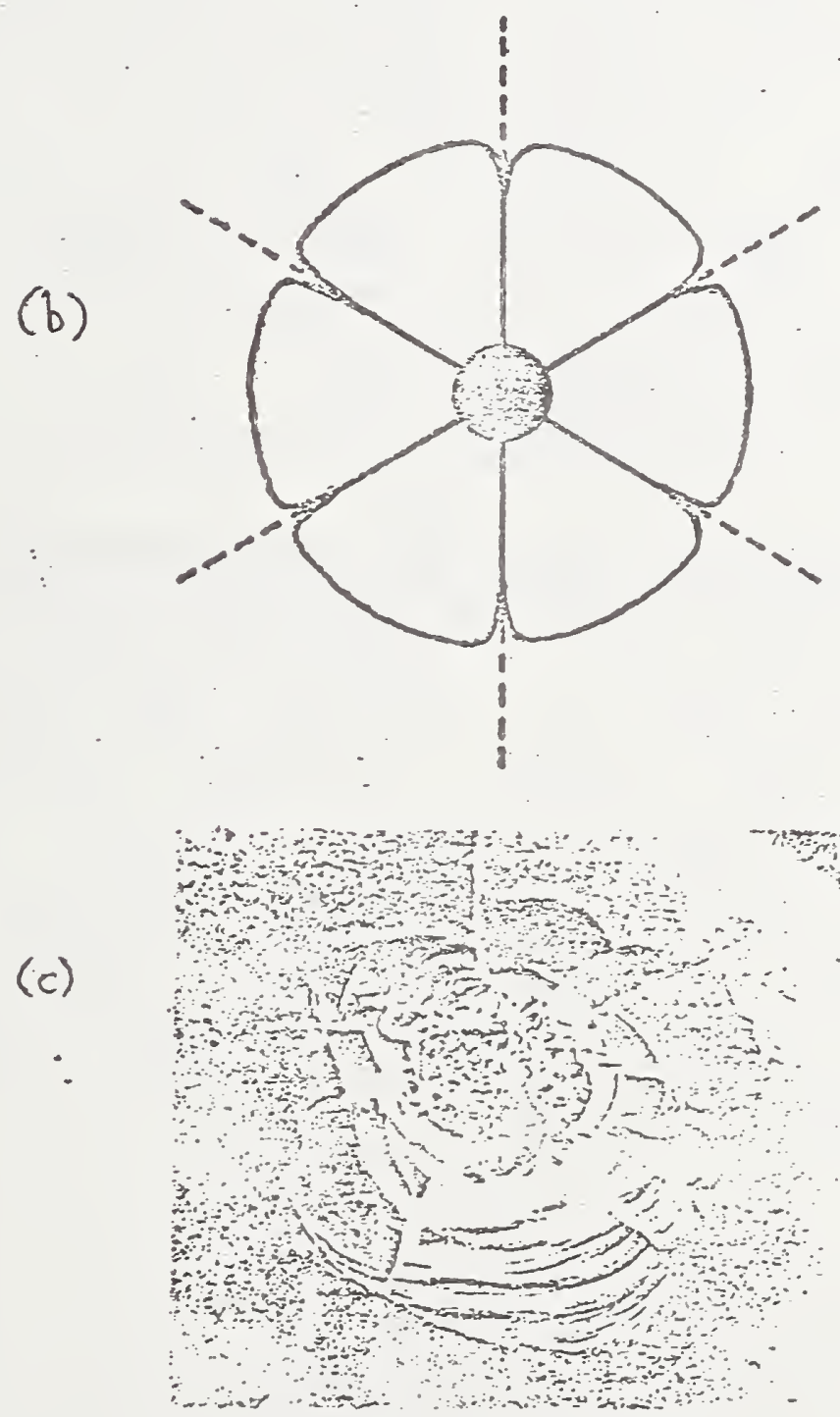

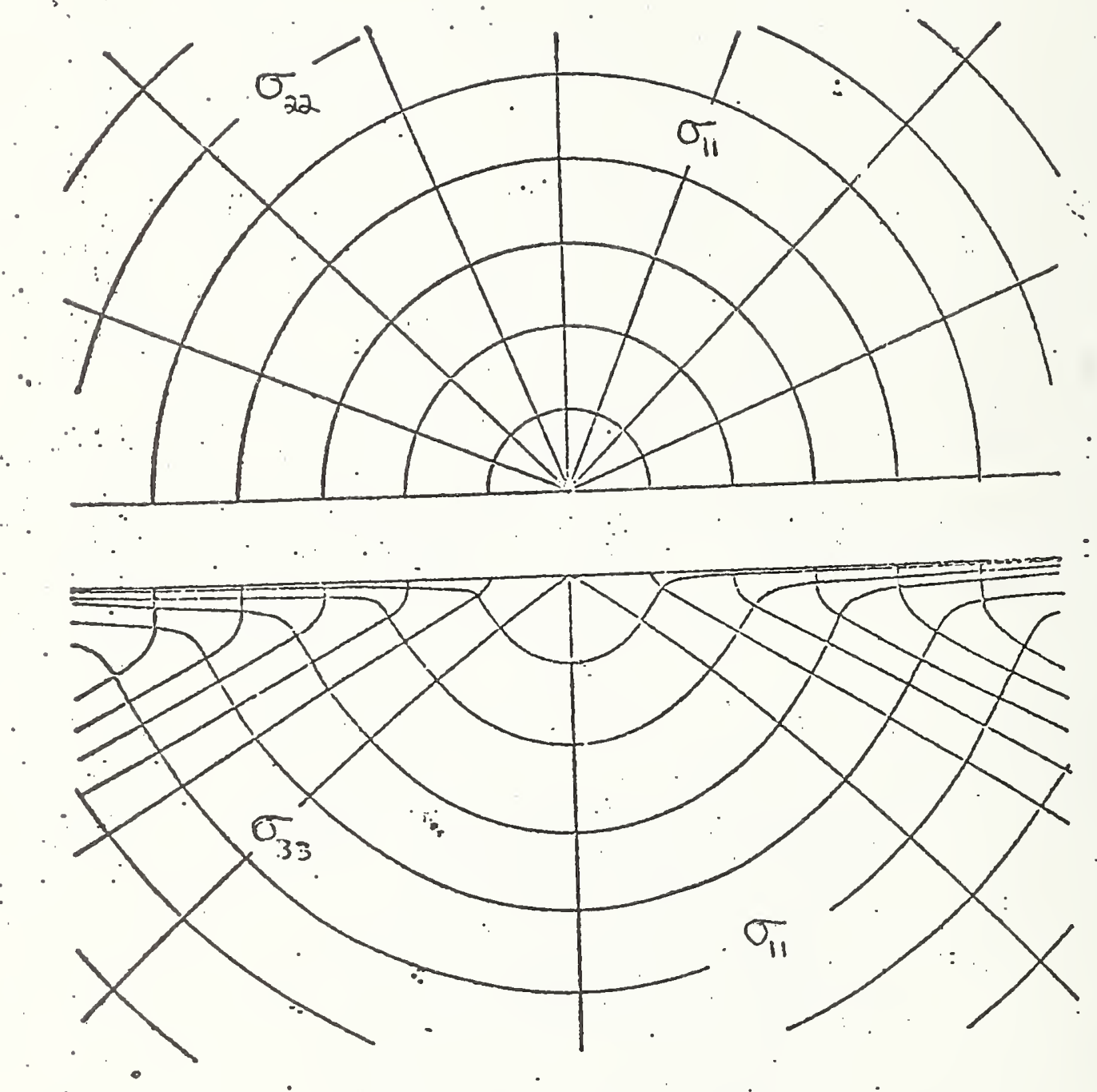
Deforination

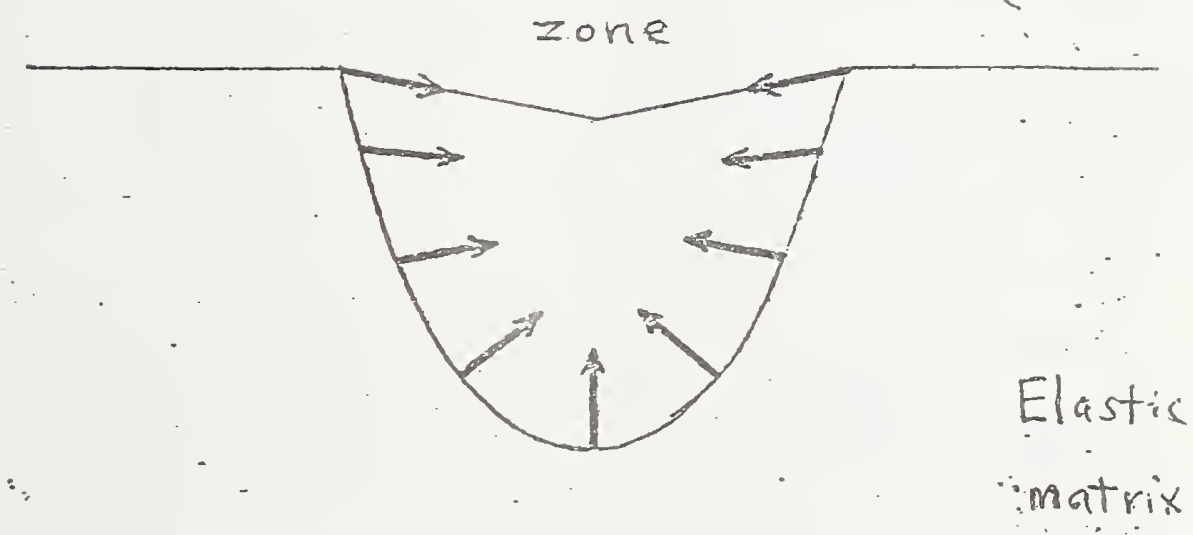

3. 



\section{Orqanization}

Office of Naval Research

Department of the Navy

Attn: Code 471

Arlington, Virginia 22217

Director

Office of Naval Research

Branch Office

495 surmer Street

Boston, Massachusetts 02210

Director

Office of Naval Research

New York Area Office

207 West 24th Street

New York, New York 10011

Director

Office of Naval Research

Branch Office

1030 East Green Street

Pasadena, California 91101

Commanding officer

Naval Weapons Laboratory

Attn: Research Division

Dahlgren, Virginia 22448

Director

Naval Research Laboratory

Attn: Technical Information officer Code 2000

Washington, D. C. 20390

Director

Naval Research Laboratory

Attn: Technical Information officer Code 2020

Washington, D. C. 20390

Director

Naval Research Laboratory

Attn: Technical Information Officer Code 6000

Washington, D. C. 20390

\section{Organization}

Director

Naval Research Laboratory

Attn: Technical Information officer code 6100

Washington, D. C. 20390

Director

Naval Research Laboratory

Attn: Technical Information officer Code 6300

Washington, D. C. 20390

Director

Naval Research Laboratory

Attn: Technical Information officer Code 6400

Washington, D. C. 20390

Director

Naval Research Laboratory

Attn: Iibrary

Code 2029 (ONRL)

Washington, D. C. 20390

Commander

Naval Air Systems Command

Department of the Navy

Attn: Code AIR 320A

Washington, D. C. 20360

Commander

Naval Air System Command

Department of the Navy

Attn: code AIR 5203

Washington, D. C. 20360

Commander

Naval Ordnance Systems Command

Department of the Navy

Attn: Code ORD 033

Washington, D. C. 20360

Commanding officer

Naval Air Development Center

Aeronautical Materials Div.

Johnsville

Attn: code MAM

Warminster, Pa. 18974 
Commanding Officer

Naval Ordnance Laboratory

Attn: Code 210

White Oak

Silver Spring, Maryland 20910

Commander

Naval Ship Systems Comnand

Department of the Navy

Attn: Code 0342

Washington, D. C. 20360

Commanding officer

Naval Civil Engineering Laboratory

Attn: Code L70

Port Hueneme, California 93041

Commander

Naval Ship Engineering Center

Department of the Navy

Attn: Code 6101

Washington, D. C. 20360

Naval Ships R\&D Laboratory

Annapolis Division

Attn: Code $A 800$

Annapolis, Maryland 21402

Commanding officer

Naval Ships R\&D Center

Attn: Code 747

Washington, D. C. 20007

Commander Naval Weapons Center

Naval Weapons Center

Attn: Code 5560

China Lake, California 93555

\section{Commander}

Naval Underseas Warfare Center

Pasadena, California 92152

Scientific Advisor

Commandant of the Marine Corps

Attn: Code Ax

Washington, D. C. 20380
Commanding officer

Army Research Office, Durham

Box CM; Duke Station

Attn: Metallurgy \& Ceramics Div.

Durham, North Carolina 27706

Office of Scientific Research

Department of the Air Force

Attn: Solid State Div. (SRPS)

Wasḩington, D. C. 20333

Defense Documentation Center

Cameron Station

Alexandria, Virginia 22314

National Bureau of Standards

Attn: Metallurgy Division

Washington, D. C. 20234

National Bureau of Standards

Attn: Inorganic Materials Div.

Washington, D. C. 20234

Atomic Energy Commission

Attn: Metals \& Materials Branch Washington, D. C. 20545

Argonne National Laboratory

Metallurgy Division

P. O. Box 299

Lemont, Illinois 60439

Brookhaven National Laboratory

Technical Information Division

Attn: Research Library

Upton, Long Island, New York 11973

Iibrary

Bldg. 50, Room 134

Lawrence Radiation Laboratory

Berkeley, California 94720

Los Alamos Scientific Laboratory

P. O. Box 1663

Attn: Report Librarian

Ios Alamos, New Mexico 87544

Commanding officer

Army Materials and Mechanics

Research Center

Attn: Res. Programs office (AMXMR-P)

Watertown, Massachusetts 02172 
Director

Metals \& Ceramics Division

Oak Ridge National Laboratory

P. O. BoX X

Oak Ridge, Tennessee 37830

Commanding officer

Naval Underwater Systems Center

Newport, Rhode Island 02844

Aerospace Research Laboratories

Wright-Patterson AFB

Building 450

Dayton, Ohio 45433

Defense Metals Information Center Battelle Memorial Institute

$505 \mathrm{King}$ Avenue

Columbus, Ohio 43201

Army Electronics Command

Evans Signal Laboratory

Solid State Devices Branch

c/o Senior Navy Liaison Officer

Fort Monmouth, New Jersey 07703

Commanding General

Department of the Army

Erankford Arsenal

Attn: ORDBA-1320, 64-4

Philadelphia, Pennsylvania 19137

Executive Director

Materials Advisory Board

National Academy of Sciences

2101 Constitution Avenue, N. W.

Washington, D. C. 20418

NASA Headquarters

Attn: Code RRM

Washington, D. C. 20546

Air Force Materials Lab

Wright-Patterson AFB

Attn: MAMC

Dayton, Ohio 45433
Air Force Materials Lab

Wright-Patterson AFB

Attn: MAAM

Dayton, Ohio 45433

Deep Submergence Systems Project

Attn: DSSP-00111

Washington, D. C. 20360

Advanced Research Projects Agency

Attn: Director, Materials Science

Washington, D. C. 20301

Department of the Interior

Bureau of Mines

Attn: Science \& Engineering Advisor Washington, D. C. 20240

Defense Ceramics Information Center

Battelle Memorial Institute

505 King Avenue

Columbus, Ohio 43201

National Aeronautics \& Space Adm.

Lewis Research Center

Attn: Librarian

21000 Brookpark Rd.

Cleveland, Ohio 44135

Naval Missile Center

Materials Consultant

Code 3312-1

Point Mugu, California 93041

Commanding officer

Naval Weapons Center Corona Iabs.

Corona, California 91720

Commander

Naval Air Test Center

Weapons Systems Test Div. (Code OlA)

Patuxent River, Maryland 20670

Director

Ordnance Research Laboratory

P. O. Box 30

State College, Pennsylvania 16801 
Director

Applied Physics Laboratory

1013 Northeast Eortieth st.

Seattle, Washington 98105

Materials Sciences Group

Code 5130.1

271 Catalina Boulevard

Navy Electronics Laboratory

San Diego, California 92152

Dr. Waldo K. Iyon

Director, Arctic Submarine Laboratory

Code 90, Building 371

Naval Undersea R\&D Center

San Diego, California 92132

Dr. R. Nathan Katz

Ceramics Division

U.S. Army Materials \& Mechanics

Research Center

Watertown, Mass. 02172 
Professor R. Roy

Materials Research Laboratory

Pennsylvania State University

University Park, Pennsylvania 16802

Professor D. H. Whitmore

Department of Metallurgy

Northwestern University

Evanston, Illinois 60201

Professor J.A. Pask

Department of Mineral Technology

University of California

Berkeley, California 94720

Professor D. Turnbull

Div. of Engineering and Applied Sci.

Harvard University

Pierce Hall

Cambridge, Massachusetts 02100

Dr. T. Vasilos

AVCO Corporation

Research and Advanced Development Div. 201 Lowell st.

Wilmington, Massachusetts 01887

Dr. H. A. Perry

Naval Oranance Laboratory

Code 230

Silver Spring, Maryland 20910

Dr. Paul Smith

Crystals Branch, Code 6430

Naval Research Laboratory

washington, D. C. 20390

Dr. A. R. C. Westwood

RIAS Division

Martin-Marietta Corporation

1450 South Rolling Road

Baltimore, Maryland 21227

Dr. W. Haller

Chief, Inorganic Glass Section

National Bureau of Standards

Washington, D. C. 20234
Dr. R. H. Doremus

General Electric Corporation

Metallurgy and Ceramics Lab.

Schenectady, New York 12301

Professor G. R. Miller

Department of Ceramic Engineering University of Utah

Salt Lake City, Utah 84112

Dr. T. D. Chikalla

Fuels and Matls. Department

Battelle Northwest

P. O. Box 999

Richland, Washington 99352

Mr. I . Berman

Army Materials and Mechanics

Research Center

Watertown, Massachusetts 02171

Dr. F. F. Lange

Westinghouse Electric Corporation

Research Laboratories

Pittsburgh, Pennsylvania 15235

Professor H. A. McKinstry

Pennsylvania State University

Materials Research Laboratory

University Park, Pa. 16802

Professor T. A. Litovitz

Physics Department

Catholic University of America

washington, D. C. 20017

Dr. R. J. Stokes

Honeywell Corporate Research Center 10701 Lyndale Avenue South

Bloomington, Minnesota 55420 
Dr. Harold Liebowitz

Dean of Engineering

George Washington Univeristy

Washington, D. C. 20006

Dr. H. Kirchner

Ceramic Finishing Company

P. O. Box 498

State College, Pennsylvania 16801

Professor A. H. Heuer

Case Western Reserve University

University Circle

Cleveland, Ohio 44106

Dr. D. E. Niesz

Battelle Memorial Institute

505 King Avenue

Columbus, Ohio 43201

Dr. F. A. Kroger

University of Southern California

University Park

Los Angeles, California 90007

Dr. Sheldon M. Wiederhorn

National Bureau of Standards

Inorganic Materials Division

Washington, D. C. 20234

Dr. C. O. Hulse

United Aircraft Research Labs

United Aircraft Corporation

East Hartford, Connecticut 06108

Professor M. H. Manghnani

University of Hawaii

Hawaii Institute of Geophysics

2525 Correa Road

Honolulu, Hawaii 96822

Dr. Stephen Malkin

Department of Mechanical Engineering

University of Texas

Austin, Texas 78712

Prof. H. E. Wilhelm

Department of Mechanical Engineering Colorado State University

Fort Collins, Colorado 30521
Stanford University

Dept. of Materials Sciences

stanford, California 94305

Dr. R. K. MacCrone

Department of Materials Engineering

Rensselaer Polytechnic Institute

Troy, New York 12181

Dr. D. C. Mattis

Belfer Graduate School of Science

Yeshiva University

New York, New York 10033

Professor R. B. Williamson

College of Engineering

University of California

Berkeley, California 94720

Professor R.. W. Gould

Department of Metallurgical

and Materials Engineering

College of Engineering

University of Florida

Gainesville, Florida 32601

Professor V. S. Stubican

Department of Materials Science

Ceramic science Section

Pennsylvania State University

University Park, Pennsylvania 16802

Dr. R. C. Anderson

General Electric Company

Miniature Lamp Department

Nela Park

Cleveland, Ohio 44112

Dr. Bert Zauderer

MHD Program, Advanced Studies

Room L-9513-VFSC

General Electric Company

P. O. Box 8555

Philadelphia, Pennsylvania 19101

Prof. C. F. Fisher, Jr.

Department of Mechanical and Aero-

Space Engineering

University of Tennessee

Knoxville, Tennessee 37916 


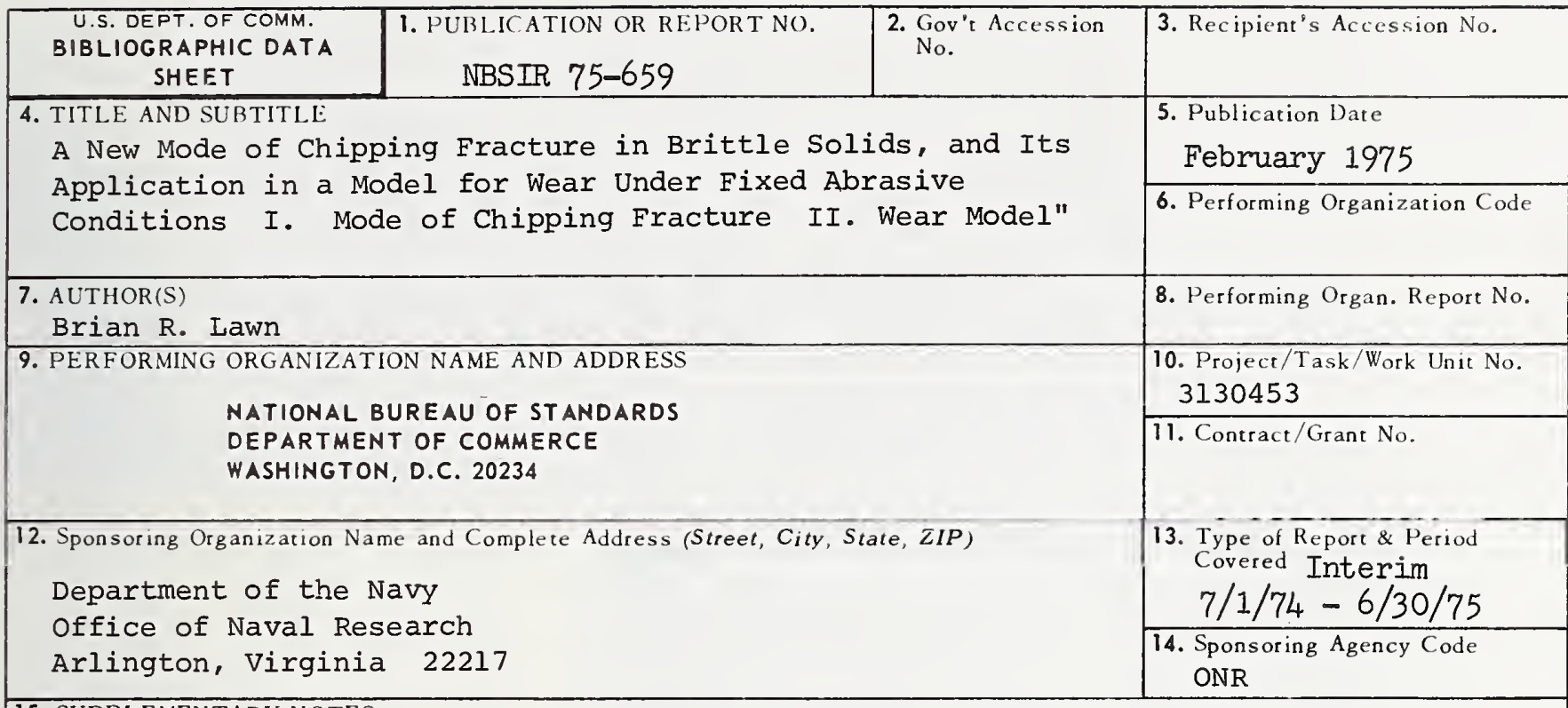

15. SUPPLEMENTARY NOTES

16. ABSTRACT (A 200-word or less factual summary of most significant in formation. If document includes a significant bibliography or literature survey, mention it here.)

A description is given of the mode of chipping fracture observed in highly brittle solids. It is pointed out that residual stresses about indentation deformation centers play a vital role. The implications of this mode in a number of mechanical phenomena are discussed.

An explicit model for the wear of brittle surfaces under fixed abrasive conditions is presented in terms of indentation fracture concepts. The predicted wear rate for glass agrees with that observed experimentally to within an order of magnitude. Some implications concerning the parameters which influence the abrasion process, particularly the hardness, are discussed.

17. KEY WORDS (six to twelve entries; alphabetical order; capitalize only the first letter of the first key word unless a proper name; separated by semicolons)

Abrasion; brittle solids; brittle surfaces; chipping; fracture; hardness; indentation; residual stress; stress analysis; wear rate

18. AVAILABILITY $\square$ Unlimited

XXXXF or Official Distribution. Do Not Release to NTIS

$\square$ Order From Sup. of Doc., U.S. Government Printing Office Washington, D.C. 20402, SD Cat. No. C13

$\square$ Order From National Technical Information Service (NTIS) Springfield, Virginia 22151

\begin{tabular}{|l|c|}
\hline $\begin{array}{l}\text { 19. SECURITY CLASS } \\
\text { (THIS REPORT) }\end{array}$ & 21. NO. OF PAGES \\
UNCL ASSIFIED & \\
\hline $\begin{array}{l}\text { 20. SECURITY CLASS } \\
\text { (THIS PAGE) } \\
\text { UNCLASSIFIED }\end{array}$ & 22. Price \\
\hline
\end{tabular}


